\title{
Inappropriate inferences from registry data: Pitfalls of inaccurate data handling?
}

\author{
Rahul Kakodkar ${ }^{1}$
}

Received: 26 February 2017 / Accepted: 12 March 2017 / Published online: 30 March 2017

(C) Indian Society of Gastroenterology 2017

Liver transplantation (LT) for hepatocellular carcinoma (HCC) is as old as LT itself. Even Thomas Starzl's early series of LT cases in the 1960s included patients with HCC [1]. Since a majority of HCC occur in patients with chronic liver disease or cirrhosis, the rationale for offering LT is logical: ability to simultaneously treat the tumor as well as liver disease and offer widest surgical margin with putative reduction in true recurrences as well as neo-tumor formation via elimination of the tumor generating environment [2].

Medical unsuitability, presence of large or numerous lesions, blood vessel invasion or thrombosis, metastasis and/or timely availability of a donor graft ultimately determine whether LT can be performed for a patient with HCC or not. Expansion of the liver donor pool employing extended criteria grafts (including partial and donation after cardiac death) and living liver donation has made little difference to the chronic graft shortage. The scarcity of donor grafts imbues organ allocation policy makers to distribute organs in such a manner, as to first benefit the sickest (justice model) or those who can benefit the most (utility model) from LT. The enduring controversy remains how best this can be achieved in scientifically robust yet practical terms for patients with HCC.

Prompted by unflattering survival outcomes achieved in 1970s and 1980s, in 1989, the Department of Health in the United States of America (USA) declared HCC to be contraindication for LT. The tide turned in 1996 after Mazzaferro and coworkers from Milan, Italy, reported post LT 4-year disease-free survival (DFS) of $75 \%$ and OS of $83 \%$ for patients with a single

Rahul Kakodkar

rahul.kakodkar@gmail.com

1 Dr L H Hiranandani Hospital, Hill Side Avenue, Hiranandani Gardens, Powai, Mumbai 400 076, India
$\mathrm{HCC} \leq 5 \mathrm{~cm}$ or $<3 \mathrm{HCCs} \leq 3 \mathrm{~cm}$ [3]. Hereafter referred to as Milan criteria, these size and number limits were accepted by United Network of Organ Sharing (UNOS) for graft allocation to patients with HCC in 1998 and have since served as a global benchmark of sorts. With more experience, it has become apparent that by offering LT to patients with incrementally larger tumor volume and number, equivalent survival could be attained $[4,5]$ but further expansion comes at the cost of reduced survival. The model for end-stage liver disease (MELD) score was first incorporated by UNOS for liver graft allocation in 2002. Recognizing that HCC reduces survival in patients with cirrhosis needing LT, UNOS initially accorded 24 priority MELD points (single HCC $<2 \mathrm{~cm}$ ) or 29 (as per Milan criteria) to facilitate timely transplantation before death or progression beyond Milan criteria on waiting list [6]. Soon it was observed that progression on waiting list could be controlled by non-transplant interventions like radiofrequency ablation (RFA) for small HCC and as an undesirable consequence of a policy of allocating high priority points to those even with small HCC, inordinately more transplants were being performed for $\mathrm{HCC}$ disadvantaging those without it. Also a significant number of lesions $<2 \mathrm{~cm}$ suspected to be $\mathrm{HCC}$ on preoperative imaging were turning out to be benign on explant pathology. This prompted sequential revisions to 20 and 29 MELD points, none and 24 and none and 22 for $\mathrm{HCC} \leq 2 \mathrm{~cm}$ and within Milan criteria, respectively [7].

Living donor liver transplant (LDLT) evolved in Asia to address extreme shortage of donor grafts in a region with high prevalence of liver disease and HCC due to hepatitis B. The ethical justification for LDLT in HCC rests on the principle of double equipoise where predicted survival benefit to the recipient must be significantly high for the small risk taken by the living donor to be acceptable [8].

Even the best preoperative imaging techniques can underestimate tumor burden in as many as $20 \%$ and significant progression in tumor size and number between imaging and 
LT after waiting period is not uncommon $[9,10]$. Additionally $10 \%$ to $15 \%$ nodules suspected to harbor $\mathrm{HCC}$ on pre-transplant imaging are reported benign following microscopic scrutiny of resection specimens by histopathologists [11]. As a result, any policy of complete reliance on pre-transplant imaging for assessing tumor morphology is far from infallible.

Tumor size and volume do influence survival after LT. Among patients, those with total tumor diameter $T_{\text {total }} \geq 10 \mathrm{~cm}$ are likely to have OS just $20 \%$ of those with $T_{\text {total }}<10 \mathrm{~cm}$ and those with $T_{\text {total }}>9 \mathrm{~cm}$ have DFS $50 \%$ of those with $T_{\text {total }}<9 \mathrm{~cm}$. Patients with largest nodule diameter $\left(T_{\max }\right) \geq 5 \mathrm{~cm}$ had DFS $25 \%$ of those with $T_{\max }<5 \mathrm{~cm}$ [12]. The number of tumors did not appear to impact either DFS or OS as much as size.

While size, tumor volume, tumor markers levels in blood and absence of extrahepatic disease are the commonly employed parameters in selecting HCC patients for LT, molecular, genetic and markers of invasiveness also impact post-transplant survival. High tumor grade (G2 and G3) [13] and presence of microvascular invasion $(\mathrm{mVI})$ in tumor tissue [14] predict early recurrence irrespective of tumor volume. Identification of $\mathrm{mVI}$ or vascular emboli [15] is consistently associated with poor DFS after LT, but both can only be assessed on core biopsies, surgically resected tumor specimens or explanted livers. Many have unsuccessfully researched non-invasive markers of mVI that could reliably predict presence of $\mathrm{mVI}$ before resection or LT without biopsy. A correlation between $\mathrm{mVI}$ and size of lesion [16], number of lesions [17], desgammacarboxyprothrombin level [18, 19] and histological grade [20] but not with pre-transplant imaging features is often apparent. There is an increasing tribe of scientists that is convinced that $\mathrm{mVI}$ presence is the most important predictor of inferior DFS after LT and reliable prediction of $\mathrm{mVI}$ before LT with or without biopsy is the key to selection of patients with HCC who would benefit most from LT.

Peri and post-transplant events also tend to influence survival outcomes after LT for HCC [21]. Swiss researchers outlined a five-pronged strategy to optimize outcome of LT for HCC [22]: select patients with low baseline circulating tumor cells, decrease peri-transplant release of cells, prevent engraftment of circulating tumor cells, use anti-cancer drugs after LT and tune immunity to clear tumor cells after LT. Type of liver graft used [23, 24], recurrence of disease (hepatitis B or C, alcohol recidivism) [24-26], episodes of acute cellular rejection as well as type of maintenance immunosuppression [27] employed have been reported to impact $\mathrm{HCC}$ recurrence rates. Therefore, capturing these data for analysis seems important to ensure that the groups are comparable for accurate statistical applications to be applied and correct inferences drawn.

In this issue of the Indian Journal of Gastroenterology, ElFattah present an analysis of surveillance, epidemiology and end-results (SEER) data of patients who underwent LT for HCC. In their report titled 'Hepatocellular carcinoma biology predicts survival outcome after liver transplantation in the United States' the author conclude that primary $\mathrm{HCC} \leq 2 \mathrm{~cm}$ had an excellent prognosis after LT, which is not affected by presence of MVI or poor differentiation [28]. Since pathological features are representative of tumor biology, the contradiction between the title and their most prominent conclusion is striking.

A cancer registry is a systematic collection of data about cancer including history, diagnosis, treatment and status. While registry data does present opportunities for research, there are inherent challenges to making appropriate references and clinical recommendation based on them. Before analyzing the registry data for meaningful inferences to be drawn, certain boxes need to be ticked [29]. First, the analytic population must be truly representative of the total population of the database to eliminate bias. Secondly, one must consider whether all the important covariates were collected, whether the data were complete and whether the missing data were handled appropriately. To be meaningful, the registry should have accurate, well defined and complete information including potential confounding and effect modifying factors. Missing data needs to be assessed not just for what is missing but also why it is missing and the data appropriately censored if needed. Without this process, simple exclusion of missing data, while convenient, tends to introduce elements of bias making the analytic population less representative of the target population of the registry.

SEER is an authoritative source of information on cancer incidence and mortality in the United States of America currently covering $28 \%$ of the population. It includes data for HCC incidence, patient demographics, treatment and survival it does not capture liver transplant specific data like waiting period, bridging procedures while waiting, type of transplant, post-transplant immunosuppression all of which are known to influence survival.

For the analysis El-Fattah, retrieved data of 1162 patients from the SEER database who underwent LT from primary HCC $\leq 5 \mathrm{~cm}$ between 2004 and 2012 [28]. Of these, final cohort had 570 cases after excluding those diagnosed at autopsy or death, without active follow up and cases with incomplete information of follow up time, alpha-fetoprotein (AFP) and pathologic data and those with fibrolamellar HCC. For statistical analysis, they used a cutoff size of $2 \mathrm{~cm}$ guided by the findings of other studies that prognostic role of $\mathrm{mVI}$ disappears for $\mathrm{HCC} \leq 2 \mathrm{~cm}$ [30]. The median tumor size of this cohort was only $2.5 \mathrm{~cm}$ (range $1.5-3.2 \mathrm{~cm}$ ) and the largest only $3.2 \mathrm{~cm}$ although the data for solitary $\mathrm{HCC} \leq 5 \mathrm{~cm}$ was under consideration. The size of tumor was determined on pre-transplant imaging but the mode of imaging and time period between last imaging and LT surgery is not clarified. There is no data available or analyzed pertaining to duration from detection to transplant, presence or absence of chronic liver disease, etiology of liver disease or details of bridging procedures performed in the waiting period. The type of transplant performed (whole liver vs. partial graft), donor (living 
vs. deceased), underlying liver quality (cirrhosis vs. fibrosis vs. normal liver) that have been shown to influence CSS in other studies [23, 24] are conspicuous by their absence in this analysis.

El-Fattah. proffered that male sex, tumor size, poor differentiation and elevated pre-LT AFP was associated with significantly higher prevalence of HCC with $\mathrm{mVI}$ while age, race, marital status and year of diagnosis were not. Poor histological differentiation was significantly more frequently encountered in $\mathrm{HCC}>2 \mathrm{~cm}$, patients of Asian descent and those with elevated pre-LT AFP but age, sex, year of diagnosis and marital status did not seem to have any bearing. For the entire analyzed cohort of 570, 1-, 3-, 5- and 7-year cancer specific survival (CSS) was $97 \%, 92 \%, 87 \%$, and $84 \%$, respectively. Individuals aged $>60$, with tumor size $>2 \mathrm{~cm}$ and elevated preLT AFP experienced poorer CSS but there was no impact of gender or marital status.

The 1-, 3-, and 5-year OS as well as CSS was inferior in the $\mathrm{mVI}+$ group but presence or absence of $\mathrm{mVI}$ had no bearing on 1-, 3-, and 5-year CSS in those with HCC $\leq 2 \mathrm{~cm}$. In HCC $>2 \mathrm{~cm}$, mVI presence increased risk of cancer specific mortality 2.26 fold. It is well known that smaller HCC tend to have less $\mathrm{mVI}$. This was also borne out in this analysis (10.4\% for $\leq 2 \mathrm{~cm}$ and $19.5 \%$ for $>2 \mathrm{~cm}$ ). Since $\mathrm{mVI}$ was relatively rare (less than 1 in 10 cases of lesions $\leq 2 \mathrm{~cm}$ ) as compared to other studies [31], it is debatable whether such conclusion drawn can be directly applied prospectively to selection of LT for $\mathrm{HCC} \leq 2 \mathrm{~cm}$. This issue would have been better elucidated had two matched groups of LT recipients with $\mathrm{HCC} \leq 2 \mathrm{~cm}$ with and without $\mathrm{mVI}$ based on pre-transplant assessment were compared. With priority MELD points allocated by UNOS in early 2000s and subsequent emergence of nonsurgical interventions as competing strategies for small $\mathrm{HCC}$, it is quite unlikely that patients with $\mathrm{HCC} \leq 2 \mathrm{~cm}$ would undergo upfront LT in sufficient numbers for these data to be validated or even relevant in the future.

Poor differentiation was associated with significantly poorer OS and CSS at 1, 3, and 5 years than well or moderately differentiated HCC. After adjusting for age, mVI, AFP and gender, those with poorly differentiated HCC had 2.26fold higher risk of cancer specific mortality only among those with size $>2 \mathrm{~cm}$.

Age $>60$, presence of $\mathrm{mVI}$ and poor differentiation were predictors of inferior CSS in those with $\mathrm{HCC}>2 \mathrm{~cm}$ but these had no significant impact on CSS when tumor size was $\leq 2 \mathrm{~cm}$. Since only $6.3 \%$ of tumors $\leq 2 \mathrm{~cm}$ had poor differentiation, similar concerns need to be raised regarding whether this statistical conclusion can be extrapolated or externally validated to less 'privileged' cohorts than the one analyzed by El-Fattah.

Based on their statistical analysis, acknowledging the obvious limitations of their study, El-Fattah recommend that tumor size of solitary HCC be included in American Joint Committee on Cancer (AJCC) staging system and resection for pathological assessment is unnecessary while offering LT for $\mathrm{HCC} \leq 2 \mathrm{~cm}$ except in elderly patients ( $>60$ years). These conclusions while tantalizing if reproducible and applicable to general population, fall short on rigorous scrutiny for aforementioned reasons. While the authors deserve to be commended for their efforts, in the real world scenario, until the severe graft shortage is overcome, almost no patient with solitary HCC $\leq 2 \mathrm{~cm}$ will be offered upfront liver transplantation using a deceased donor organ. Since MELD priority points were awarded by UNOS from 2002 even for lesions $\leq 2 \mathrm{~cm}$, the SEER data probably included significant numbers of such cases before revision of points by UNOS. Mathematical models have computed that unless there is more than $30 \%$ progression related wait list dropout among patients and more than $10 \%$ waitlisted patients for LT have HCC as indication, preferential allocation to HCC patients increases wait list mortality among those not having HCC [32].

With no priority points on offer for small lesions any longer, such data are unlikely to be reproducible and available for analysis in the USA. Where living donor situation is prevalent, in single $\mathrm{HCC} \leq 2 \mathrm{~cm}$, liver resection if feasible or a nonsurgical option like RFA or transarterial chemoembolization and salvage LDLT would be the most commonly offered option at most centers. This strategy comes without risk to the living donor and many studies have demonstrated salvage transplant to offer equivalent outcomes [33]. Some have recommended pre-emptive LT for those with $\mathrm{mVI}+$ in resection specimens, but there is no consensus yet in this regard [34].

Although suffering from limitations regarding data quality, representativeness of analyzed population, incompleteness of covariates, the analysis performed by El-Fattah. reaffirms two important facts: that LT is an effective and durable treatment for HCC and selection of candidates based on tumor morphology and biology (grade and $\mathrm{mVI}$ ) is an important determinant of post-transplant outcome. However, a focused prospectively maintained database of patients with HCC who have undergone LT that captures data of pre-transplant, peri-transplant and post-transplant variables will need to be analyzed for making inferences that could be applied to the general population and aid clinical decision making. In earnest hope, we await such a holy grail.

\section{References}

1. Starzl TE, Porter KA, Brettschneider L, et al. Clinical and pathologic observations after orthotopic transplantation of the human liver. Surg Gynecol Obstet. 1969;128:327-39.

2. Kakodkar R, Soin AS. Liver transplantation for HCC: a review. Indian J Surg. 2012;74:100-17.

3. Mazzaferro V, Regalia E, Doci R, et al. Liver transplantation for the treatment of small hepatocellular carcinomas in patients with cirrhosis. N Engl J Med. 1996;334:693-9. 
4. Yao FY, Ferrell L, Bass NM, et al. Liver transplantation for hepatocellular carcinoma: expansion of the tumor size limits does not adversely impact survival. Hepatology. 2001;33:1394-403.

5. Mazzaferro V, Llovet JM, Miceli R, et al. Predicting survival after liver transplantation in patients with hepatocellular carcinoma beyond the Milan criteria: a retrospective exploratory analysis. Lancet Oncol. 2009; 10:35-43.

6. Freeman RB, Wiesner RH, Edwards E, Harper A, Merion R, Wolfe $R$. Results of the first year of the new liver allocation plan. Liver Transpl. 2004;10:7-15.

7. Sharma P, Balan V, Hernandez JL, et al. Liver transplantation for hepatocellular carcinoma: the MELD impact. Liver Transpl. 2004;10:36-41.

8. Miller CM. Ethical dimensions of living donation: experience with living liver donation. Transplant Rev (Orlando). 2008;22:206-9.

9. Roayaie S, Frischer JS, Emre SH, et al. Long-term results with multimodal adjuvant therapy and liver transplantation for the treatment of hepatocellular carcinomas larger than 5 centimeters. Ann Surg. 2002;235:533-9.

10. Marsh JW, Dvorchik I. Liver organ allocation for hepatocellular carcinoma: are we sure ? Liver Transpl. 2003;9:693-6.

11. Germani G, Gurusamy K, Garcovich M, et al. Which matters most: number of tumors, size of the largest tumor, or total tumor volume? Liver Transpl. 2011;17 Suppl 2:S58-66.

12. Gouw AS, Balabaud C, Kusano H, Todo S, Ichida T, Kojiro M. Markers for microvascular invasion in hepatocellular carcinoma: where do we stand? Liver Transpl. 2011;17 Suppl 2:S72-80.

13. Tamura S, Kato T, Berho M, et al. Impact of histological grade of hepatocellular carcinoma on the outcome of liver transplantation. Arch Surg. 2001;136:25-30. discussion 31

14. Jonas S, Bechstein WO, Steinmüller T, et al. Vascular invasion and histopathologic grading determine outcome after liver transplantation for hepatocellular carcinoma in cirrhosis. Hepatology. 2001;33: 1080-6.

15. Esnaola NF, Lauwers GY, Mirza NQ, et al. Predictors of microvascular invasion in patients with hepatocellular carcinoma who are candidates for orthotopic liver transplantation. J Gastrointest Surg. 2002;6:224-32. discussion 232

16. Hoshida Y, Villanueva A, Kobayashi M, et al. Gene expression in fixed tissues and outcome in hepatocellular carcinoma. N Engl J Med. 2008;359:1995-2004.

17. Pawlik TM, Delman KA, Vauthey JN, et al. Tumor size predicts vascular invasion and histologic grade: implications for selection of surgical treatment for hepatocellular carcinoma. Liver Transpl. 2005;11:1086-92.

18. Fujiki M, Takada Y, Ogura Y, et al. Significance of des-gammacarboxy prothrombin in selection criteria for living donor liver transplantation or hepatocellular carcinoma. Am J Transplant. 2009;9:2362-71.

19. Cherqui D, Boudjema K, Celebic A, Laurent A. Roudot-Thoraval F. Resection hepatique pour carcinome hepatocellulaire sur foie sain et pathologique en France. Resultats de lenquete AFC sur la periode 1990-2005. In: Boudjema K, Cherqui D, eds. Cancer
He'patocellulaire.Rueil-Malmaison. Paris: Wolters Kluwer; 2006. p. $183-218$.

20. Sumie S, Kuromatsu R, Okuda K, et al. Microvascular invasion in patients with hepatocellular carcinoma and its predictable clinicopathological factors. Ann Surg Oncol. 2008;15:1375-82.

21. Gu XQ, Zheng WP, Teng DH, Sun JS, Zheng H. Impact of nononcological factors on tumor recurrence after liver transplantation in hepatocellular carcinoma patients. World J Gastroenterol. 2016;22:2749-59.

22. Toso C, Mentha G, Majno P. Liver transplantation for hepatocellular carcinoma: five steps to prevent recurrence. Am J Transplant. 2011;11:2031-5.

23. Vakili K, Pomposelli JJ, Cheah YL, et al. Living donor liver transplantation for hepatocellular carcinoma: increased recurrence but improved survival. Liver Transpl. 2009;15:1861-6.

24. Lo CM, Fan ST, Liu CL, Chan SC, Ng IO, Wong J. Living donor versus deceased donor liver transplantation for early irresectable hepatocellular carcinoma. Br J Surg. 2007;94:78-86.

25. Wu TJ, Chan KM, Chou HS, et al. Liver transplantation in patients with hepatitis B virus-related hepatocellular carcinoma: the influence of viral characteristics on clinical outcome. Ann Surg Oncol. 2013;20:3582-90.

26. Kohli V, Singhal A, Elliott L, Jalil S. Antiviral therapy for recurrent hepatitis $\mathrm{C}$ reduces recurrence of hepatocellular carcinoma following liver transplantation. Transpl Int. 2012;25:192-200.

27. Cholongitas E, Mamou C, Rodríguez-Castro KI, Burra P. Mammalian target of rapamycin inhibitors are associated with lower rates of hepatocellular carcinoma recurrence after liver transplantation: a systematic review. Transpl Int. 2014;27:1039-49.

28. El-Fattah MA. Hepatocellular carcinoma biology predicts survival outcome after liver transplantation in the USA. Indian J Gastroenterol. 2017; doi:10.1007/s12664-017-0732-x.

29. Gliklich R, Dreyer N, Leavy M, eds. Registries for evaluating patient outcomes: a user's guide. 3rd Edition. Two Volumes. Outcome Sciences Inc. 2014.

30. Shindoh J, Andreou A, Aloia TA, et al. Microvascular invasion does not predict long term survival in hepatocellular carcinoma upto $2 \mathrm{~cm}$ : reappraisal of the staging system for solitary tumors. Ann Surg Oncol. 2013;20:1223-9.

31. Ünal E, İdilman İS, Akata D, Özmen MN, Karçaaltıncaba M. Microvascular invasion in hepatocellular carcinoma. Diagn Interv Radiol. 2016;22:125-32.

32. Cucchetti A, Vitale A, Gaudio MD, et al. Harm and benefits of primary liver resection and salvage transplantation for hepatocellular carcinoma. Am J Transplant. 2010;10:619-27.

33. Li HY, Wei YG, Yan LN, Li B. Salvage liver transplantation in the treatment of hepatocellular carcinoma: a meta-analysis. World J Gastroenterol. 2012;18:2415-22.

34. Fuks D, Dokmak S, Paradis V, Diouf M, Durand F, Belghiti J. Benefit of initial resection of hepatocellular carcinoma followed by transplantation in case of recurrence: an intention-to-treat analysis. Hepatology. 2012;55:132-40. 